\title{
EVALUATION OF THE CONTROL OF ONCHOCERCIASIS THROUGH COMMUNITY-DIRECTED TREATMENT WITH IVERMECTIN (CDTI) IN SELECTED VILLAGES OF JOS EAST LOCAL GOVERNMENT AREA, PLATEAU STATE
}

P. JOAN, J. KAMANI, P. N.OKAM AND R.Y. ARIN

(Received 17, June 2008; Revision Accepted 3, February 2009)

\begin{abstract}
Community Directed mass ivermectin ${ }^{\circledR}$ treatment (CDTI) programme of the National Onchocerciasis control was evaluated in five randomly selected villages in Jos East Local Government Area by clinical and parasitological methods. Oral interview using structured questionnaire was used to asses awareness and level of drug compliance. A total of 452 persons from the study area were selected by stratified random sampling for clinical and parasitological evaluation. An overall prevalence of $15.7 \%$ was observed using both clinical and parasitological assessment. Clinically, $30(5.5 \%) ; 32(5.9 \%) ; 4(0.7 \%)$ and $3(0.6 \%)$ persons were manifesting leopard skin, nodules, hanging groin and elephantiasis lesions respectively. Parasitological examination by skin biopsy revealed that only $2(0.4 \%)$ persons were positive for microfilaria of Onchocerca volvolus, which is an indication of a decrease in active cases among the population. All the positive cases confessed non compliance with drug use. Generally there appears to be a remarkable decrease in the prevalence of Onchocerciasis in the study area compared to earlier report of $27.9 \%$ in the 1980's. This could be attributed to efficacy of ivermectin and increased awareness among the general public of the need on compliance with the drug. Concerted and coordinated mass enlightenment should be sustained to eradicate the pockets of active cases to eliminate all possible sources of infection.
\end{abstract}

KEY WORDS: Onchocerciasis; Community, Ivermectin, Control; Evaluation; Jos-east.

\section{INTRODUCTION}

Onchocersiasis is caused by the parasite, Onchocerca volvulus, which infects humans via the bite of the intermediate host, Simulium spp (Elmer and Glenn, 1982). Previous studies demonstrated that onchocerciasis in West Africa exists in two forms, which differ in their clinical and epidemiologic characteristics (Ade et.al, 1999). This is believed to be due to the existence of 2 strains of Onchocerca volvulus, the causative agent of onchocerciasis. Manifestations of the disease include disabling itching, severe skin disease and, after repeated years of exposure, blindness (Buck, 1974, Soulsby, 1982, Barry and William, 1996). One of the primary methods of halting transmission is centered on vector control; consist of weekly aerial applications of environmentally-safe insecticides to the black fly's breeding areas (Miri, 1998). The other method focuses on annual drug treatment. Presently no drug exists to kill the adult parasite worm; larval worms can be killed with a single, annual dose of ivermectin (Obinna et.al, 2001). Since the larval worms is actually responsible for the manifestations of the disease and allow for its transmission, the drug is extremely effective. It reduces the load of larval worms, thereby relieving the suffering of the infected individual and eliminating the threat of blindness while simultaneously slowing the transmission of the disease. However, to sustain these beneficial effects, ivermectin must be taken annually over an extended period. According to a prevalence survey in 1986, over 7 million persons in at least 32 states of Nigeria are estimated to be at risk of Onchocerciasis.

The onchocerciasis control programme in Plateau state, Nigeria, was one of the pioneering ivermectin distribution projects in Nigeria. Although initiated under the River Blindness Foundation (RBF) in 1991, in collaboration with the Ministry of Health, it was absorbed into the Carter Center's Global 2000 River Blindness Programme (GRBP) in 1996. The objectives of the programme were to support the delivery of ivermectin, to at least $80 \%$ of those living in communities where onchocerciasis was highly endemic. The challenge now is to learn how to transform this functional, programme-designed and programmedirected effort into the new community-directed treatment being promoted by the African Programme for Onchocerciasis Control. This study was designed to evaluate the effectiveness of the CDTI in the control of Onchocerchiasis in Jos East Local Government Area, Plateau State.

\section{MATERIALS AND METHODS}

\section{Study area}

Jos East local Government Area is one of the Onchocerciasis endemic areas of Plateau State and

P. Joan, Parasitology Division NVRI, PMB 01 Vom, Plateau State.

J. Kamani, Parasitology Division NVRI, PMB 01 Vom, Plateau State.

P. N. Okam, NITOR, VOM Nigeria

R.Y Arin, Diagnostic division NVRI Vom 
share border with Bauchi State. It lies between latitude $8.30^{\circ}$ and $9^{\circ} \mathrm{N}$ and longitude $9.30^{\circ}$ and $10^{\circ} \mathrm{E}$. The grass vegetation is interspersed with farms and thick bush trees such as Shea butter tree (Butyrospermum parkii) and Acacia albida. Also found in the zone are Locust Bean Tree (Parkia filicoidea) and Euphoribias trees. Fast lowing streams abound in the area and serves as tourist centre. Major occupation is farming, fishing and few public servants and nomadic Fulani's.

\section{Survey and Sampling}

Five villages were randomly selected from the districts of Jos East Local Government Area for the study. The study was conducted by physical examination and interview using structured questionnaires and skin snips for parasitological examination. Respondents were asked if they had ever received ivermectin and if they had been consistent in taking the drug over the years.

They were then physically assessed before skin snip is taken according to WHO (1976). Snips were taken from the scapula, iliac crest and calf using corneo scleral punch for each respondent and kept separately in 3 wells of flat bottom microtitre plates containing 3 drops of Tyrode's solution. The punch was thoroughly cleansed with methylated spirit, left to dry, then flamed to avoid contamination and possible transmission of diseases between subjects.

Physical examination of respondents for evidence of skin changes such as dermatitis, pruritis, leopard skin, lymphedema and palpable nodules was conducted. Visual acuity was determined by the method described by Budden, (1956).

\section{Laboratory Processing and Examination}

In the laboratory the individual well of the microtitre plate was examined for presence of the larval stage (microfilaria) of Onchocerca using inverted microscope. Positive wells were pippetted onto a clean grease free microscope slide, air dried, fixed in absolute methanol and stained with Mayer's alum haematoxylin for identification of microfilaria.

\section{RESULTS}

An overall prevalence of $15.7 \%$ Onchocerca lesion was recorded in the area examined. The highest prevalence of $28.3 \%$ was recorded in Maijuju village followed by $16 \%$ in Fursum while the least $7.5 \%$ was recorded in Fewit village (Table 1).

Onchocerca lesions seen were; nodules ( $n=32$ or $7.1 \%$ ), leopard skin ( $n=30$ or $6.6 \%$ ), hanging groin $(n=7$ or $1.5 \%)$ and elephantiasis $(n=3$ or $0.7 \%)$. The results also showed that most positive cases were farmers and housewives followed by civil servants and students (Table 2). The only two positive cases for skin snip examination were housewives both in Natong village.
More females ( $n=52$ or $24.9 \%$ ) than males ( $n=19$ or $6.9 \%$ ) were showing Onchocerca lesions, although there was no significant statistical difference $(P>0.05)$ using Student T-test at 95 confidence interval.

\section{DISCUSSION}

Onchocerciasis remains an important public health problem throughout much of sub-Saharan Africa despite several control measures. Plateau State has been identified as one of the endemic areas in Nigeria. The control of Onchocerciasis in Plateau State commenced in 19991 using ivermectin distributed to $80 \%$ of those living in communities where Onchocerca was highly endemic for the first 3 years and maintained for a period of 10-15 years (Miri, 1998). From the result of this study prevalence of Onchocerciasis in Jos East Local Government area of Plateau State has shown a remarkable decline from $26 \%$ earlier reported to $16.2 \%$ over a period of 5 years. A similar report was made by Pion et al (2004) after a four years assessment of Ivermectin treatment in the Mbam Valley of Cameroon. This may be as a result of the introduction of the community directed mass ivermectin treatment adopted as a control measure in this community. Financial constraint could militate against the successful control of Onchocerciasis as opined by Obinna et.al, (2001) thus when the drug was given free as in this case, compliance rather than affordability may be responsible for cases seen. The high prevalence of Onchocercicasis in Maijuju village compared to other villages in the study area may be related to late adoption of the CDTI in the area or lack of awareness among the villagers as shown through interviews. The few active cases as evidenced by the low positive skin snips among patients is an indication of decline in the number of new cases probably due to effective clearance of larvae from patient by ivermectin. Provision and improvement of existing social infrastructures in the area might have assisted in the reduction of the prevalence of the disease. Skin nodule, leopard skin and elephantiasis were the common lesions encountered indicating chronic cases. Farmers were the most affected group by Onchocerciasis, which may not be unconnected with their occupation as earlier reported by Kenneth et.al (2005). Few students and civil servants were affected compared to farmers possibly due to level of education and nature of profession where they have limited exposure to the fly vector.

In conclusion, there is the need to sustain ivermectin distribution in known endemic areas to completely eradicate pockets of active cases. Continued coordinated enlightenments in villages to ensure compliance with drug use as well as control fly vectors is also recommended to totally eradicate the disease from the area. 
Table 1: Distribution of Onchocerca lesion in the study area

\begin{tabular}{|c|c|c|c|c|c|c|c|}
\hline Study area & $\begin{array}{l}\text { No } \\
\text { examined }\end{array}$ & $\begin{array}{l}\text { Positive skin } \\
\text { snip }\end{array}$ & $\begin{array}{l}\text { Leopard } \\
\text { skin }\end{array}$ & Nodules & $\begin{array}{l}\text { Hanging } \\
\text { groin }\end{array}$ & Elephantiasis & Total (\%) \\
\hline Maijuju & 52 & --- & 18 & 20 & 3 & 2 & 43 \\
\hline Natong & 100 & 2 & 6 & -- & -- & -- & 8 \\
\hline Fewit & 80 & -- & -- & 5 & 1 & -- & 6 \\
\hline Doss & 70 & -- & 2 & 4 & -- & -- & 6 \\
\hline Fursum & 50 & -- & 4 & 3 & ---- & 1 & 8 \\
\hline Total & 452 & 2 & 30 & 32 & 4 & 3 & 71 \\
\hline
\end{tabular}

Table 2: Distribution of Onchocerca lesions according to gender

\begin{tabular}{|l|l|l|l|}
\hline Parameters & Male (\%) & Female (\%) & Total \\
\hline Number examined & $275(60.8)$ & $177(39.2)$ & 452 \\
Number positive & $19(6.9)$ & $52(24.9)$ & $71(15.7)$ \\
Microfilaria present & $0(0)$ & $2(1.1)$ & $2(0.4)$ \\
Leopard skin & $8(2.9)$ & $22(12.4)$ & $30(6.6)$ \\
Nodules & $6(2.2)$ & $26(14.7)$ & $32(7.1)$ \\
Hanging groin & $4(1.5)$ & $0(0)$ & $4(0.9)$ \\
Elephantiasis & $1(0.3)$ & $2(1.1)$ & $3(0.6)$ \\
\hline
\end{tabular}

Table 3: Distribution of Onchocerca lesions according to occupation

\begin{tabular}{|l|c|c|l|l|l|}
\hline Parameters & Students & House wives & Civil servants & Farmers & Total (\%) \\
\hline No examined & 70 & 52 & 30 & 300 & 452 \\
No positive & 1 & 20 & 3 & 47 & $71(15.7)$ \\
Microfilariae & 0 & 2 & 0 & 0 & $2(0.4)$ \\
Leopard skin & 0 & 6 & 1 & 23 & $30(6.6)$ \\
Nodules & 1 & 10 & 2 & 19 & $32(7.1)$ \\
Hanging groin & 0 & 0 & 0 & 4 & $4(0.8)$ \\
Elephantiasis & 0 & 2 & 0 & 1 & $3(0.7)$ \\
& & & & & \\
\hline
\end{tabular}

\section{REFERENCES}

Ogunrinade, A., Boakye, D., Merriweather, A. and Unnasch, T.R. 1999. Distribution of the Blinding and Nonblinding strains of Onchocerca volvulus in Nigeria. The Journal of Infectious Diseases 179:1577-1579

Beaty, B. J. and Marquardt, W. C., 1996. The biology of disease Vectors. University press of Colorado.

Buck, A. A., 1974. Onchocerciasis, Symptomology, Pathology and Diagnosis ed.

Budden, F. H., 1956. Epidemiology of Onchocerciasis in Northern Nigeria. Transactions of the Royal Society of the Tropical Medicine and Hygiene $50,366-378$

Noble, E. R. and Noble, G. A., 1982. Parasitology: The biology of animal parasites. $5^{\text {th }}$ edition. Lea and Fediger Philadelphia.

Opara, K. N., Fagbemi, O. B., Ekwe, A. and Okenu, D. M. N., 2005. Status of forest Onchocerciasis in the lower cross river basin, Nigeria: entomologic profile after five years of ivermectin intervention .Am. J. Trop. Med. Hyg., 73(2), 2005, pp. 371-376.
Miri, E.S., 1998. Problems and perspectives onchocerciasis control programme: a case study from Plateau state, Nigeria. Annals of Tropical Medicine and Parasitology pp121-128 (8)

Shu, O. O. E., Onwuameze, O., Ndum, C. and Okonkwo, P., 2001. Onchocerciasis control in Nigeria: Will households be able to afford community- directed treatment with ivermectin? Acta Tropical 80, (3): pp 277-281

Pion, S. D. S., Clement, M.C.A and Boussiesq, M., 2004. Impact of four years large scale ivermectin treatment with low therapeutic coverage on the transmission of Onchocerca volvulus in the Mbam valley focus, central Cameroon. Trans $R$ Soc of Trop Med and Hyg 98 (9) 520-528.

Soulsby, E. J. L., 1982. Helminths arthropods and Protozoa of domesticated animals, 7 th ed. Bailliere Tindall, London.

WHO, 1976. Expert Committee on the epidemiology of Onchocerciasis. WHO Technical Report series 597 